\title{
Las llamadas «Mujeres públicas». Historizando a través del arte
}

\section{The So-Called «Public Women». Historizing Through Art}

\section{RESUMEN}

Como resultado de un proceso de investigación que articula la historización y el análisis feminista con el visionado de dos obras de arte escénico, este artículo permite reconocer y legitimar la enorme capacidad que tiene el arte como hipertexto que trasciende los escenarios y moviliza desde la sola presencia como espectador/a. Con la intención de contribuir con la reconstrucción de un hecho histórico de relevancia feminista como lo es la expropiación de nuestros cuerpos, aquí se comparte un extracto de la historia de la prostitución en Costa Rica, o más bien de la construcción/invención histórica y patriarcal, por medio de la cual las mujeres fueron etiquetadas como «mujeres públicas», lo que se complementa con las representaciones de la obra «Vacío»². El visionado de las obras fue la fuente de información primaria a partir de la cual surge la investigación y la profundización de este análisis.

Palabras clave: desigualdad, arte, mujeres, feminismo, deconstrucción, corporalidades, análisis crítico, patriarcado y prostitución.

\begin{abstract}
As a result of an investigative process which articulates historization and feminist analysis with the observing of two works in performing arts, this article allows to recognize and legitimize the enormous capacity that art has as a hypertext that transcends the stage and mobilizes from the mere presence as a spectator. With the intention of contributing in the reconstruction of a historical fact of feminist relevance, such as the expropriation of our bodies, hereby is shared an extract of the history of prostitution in Costa Rica, or rather of the patriarchal construction/ invention of history, through which women were labelled as "public women", which is complemented with the representations of the play Vacio ${ }^{3}$. It is really the watching of these plays the primary source through which the investigation springs, and the deepening of this analysis. Keywords: Inequality, art, women, feminism, deconstruction, corporalities, critical analysis, patriarchy and prostitution.
\end{abstract}

1 Centro de Investigación en Cultura y Desarrollo CICDE-UNED, olivapatricia12@gmail.com Costa Rica. Línea de investigación: Feminismos, arte y corporalidades, poliva@uned.ac.cr

2 La obra «Vacío», creada y dirigida por Roxana Ávila (actriz y dramaturga costarricense), representa a Costa Rica en la segunda mitad del siglo XIX y principios del siglo XX, aunque una parte de la consulta e investigación se basó en la tesis doctoral de Mercedes Flores que recupera la psiquiatría en Costa Rica en 1910, el espectáculo (escenificación, vestuario y ambientación) toma como referencia, para más exactitud, las décadas de 1890 a 1960. El montaje responde a la búsqueda de formas alternativas del espacio escénico ya que, recrea un cabaret (aspecto que se toma en cuenta durante el análisis), la obra incluye un coro polifónico de mujeres, danza contemporánea, baile de salón y otras acciones físicas Interpretado por mujeres.

3 The play "Vacío», created and directed by Roxana Ávila, Costa Rican actress and playwright, represents Costa Rica in the second half of the XIX and beginning of the XX centuries, although one part of the consultation and investigation was based on the doctoral theses of Mercedes Flores which recovers psychiatry in Costa Rica in 1910, the show (staging, costumes, and setting) take as reference, to be more precise, the decades between 1860 and 1960. The staging responds to the search of alternative forms of scenic space since it recreates a cabaret (aspect covered in the analysis) has a women's polyphonic choir, contemporary dance, dancehall music, as well as other physical actions all interpreted by women. 


\section{SUMARIO}

1.- Introducción. 2.- Las llamadas «Mujeres Públicas». 3.- Enfermas mentales. 4.- Interpretación de escena/momento. 5.- Un burdel tomado por ellas. 6.- Cierre. -Referencias bibliográficas.

\section{Introducción}

El presente artículo es el segundo ${ }^{4}$ que surge de la investigación «Desde lo profundo de sus obras: Un análisis feminista sobre la expropiación del cuerpo de las mujeres», que en su ejercicio de análisis toma forma de reconstrucción histórica partiendo del visionado de las obras «Vacío», anteriormente descrita, y la obra "Augustine» ${ }^{5}$. La investigación aborda muchos otros elementos teórico-históricos sobre el control del cuerpo de las mujeres y está estructurado en tres capítulos: Capítulo 1: Historización de la locura y la persecución de las mujeres; Capítulo 2: La hospitalización y el poder de la medicina y Capítulo 3: Signos de resistencia de las mujeres. Cada uno incluye un bloque de análisis junto con una interpretación de escenas/momentos de ambas obras. La información o recuperación histórica se presenta siempre de manera intercalada entre datos teórico-históricos, debates feministas y elementos artísticos recuperados de las obras, lo que hace del análisis una lectura dinámica. La investigación recupera y visibiliza el trabajo de artistas costarricenses, no solo a través de la divulgación de las dos directoras/creadoras, sino también por la participación de un amplio elenco de mujeres artistas.

Este extracto sobre «Mujeres Públicas» se desprende del segundo capítulo, y aunque éste recupera muchas otras expresiones de violencia en relación a la práctica médica, en este artículo se hace referencia específicamente a la expropiación y control del cuerpo dentro de la dinámica de la prostitución, o más bien lo que el patriarcado consideró mujeres públicas y prácticas insanas. Como mencioné anteriormente, en la investigación se presenta la información de forma más dinámica, fusionando los textos con las expresiones artísticas, sin embargo por el límite de espacio permitido, en este artículo la información se presenta en dos partes, la primera en la que se comparten los hechos históricos y una segunda parte sobre la interpretación de escenas/momentos de la obra «Vacío», que de las dos obras es la que representa la construcción de las llamadas «mujeres públicas».

4 El primer artículo (Oliva 2017), el cual invito a revisar, es un resumen de las reflexiones finales. Su lectura puede esclarecer los objetivos y alcances de la investigación principal. Disponible en: http://investiga. uned.ac.cr/revistas/index.php/rupturas/article/view/1837. La investigación completa se puede descargar en: http://investiga.uned.ac.cr/cicde/index.php/informes-de-investigacion/209-profundo

5 «Augustine» fue creada y dirigida por Selma Solórzano, se ambienta en un pabellón destinado para el estudio de la histeria entre los siglos XIX y XX dentro del Hospital Le Salpêtrière, ubicado en Francia. Inspirada principalmente en el texto de Didi-Huberman: La invención de la histeria: Charcot y la icononografía fotográfica de la Salpêtrière (2007). Es un espectáculo multidisciplinario de danza y teatro que integra música, fotografía, videoarte y proyección multimedia. La coreografía cuenta con un cuerpo de cinco bailarinas, dos bailarines y un actor. 


\section{Las llamadas «Mujeres Públicas»}

Antes de iniciar este breve recorrido histórico sobre la construcción patriarcal de la prostitución en Costa Rica, me parece importante referirme al concepto de escisión o fragmentación de la corporalidad-sexualidad e identidad femenina que ha sido utilizado por teóricas feministas para explicar y comprender la cosificación y expropiación del cuerpo de las mujeres. Se trata de una estructuración o clasificación de las mujeres que nos ha ubicado estratégicamente en dos límites o extremos, siempre como instrumento para satisfacer placeres e intereses de otros, según Lagarde:

La sexualidad femenina tiene dos espacios vitales: uno es el de la procreación y otro es el erotismo. Estos ámbitos de la sexualidad son la base de la especialización sociocultural de las mujeres. El erotismo es el espacio vital reservado a un grupo menor de mujeres ubicadas en el lado negativo del cosmos, en el mal, y son consideradas por su definición esencial erótica como malas mujeres, se trata de las putas (Lagarde, 1990: 186).

A partir de esta especialización surgen desde luego la demarcación de roles y estereotipos que acompañarán para siempre a las mujeres: de un lado las buenas y santas, asociadas a la maternidad, labores del hogar, tenencia de los hijos e hijas, y del otro, la mujer mala, la bruja, la sucia que se ubicará fuera de los roles domésticos contraria a la madre-esposa. En su trabajo Los Secretos de Eva, Josephine Lowndes se refiere también a la existencia de dos únicas opciones en la vida de una mujer:

Durante el siglo XIX, que aún nos impone su presencia, las mujeres sólo tenían dos posibilidades: "ser ángeles o perdidas». El ideal era la mujer asexuada y se consideraban pecadoras a las que no cumplían con ese precepto (Lowndes, 1988: 11).

Dicha fragmentación sería la base del discurso que tanto el Estado y sus intereses socio-económicos en alianza total con la iglesia como principal opresora, acompañaría durante siglos la labor de persecución y expropiación del cuerpo de las mujeres. La autora Laura Chacón indica que el paradigma de lo puro/impuro ha estado presente desde la antigüedad y hasta hoy parece estar dictando normas sobre las relaciones humanas:

Me refiero no solo a la división simbólica que nuestra cultura establece entre los sexos, sino también a la frontera rígida que realiza dentro del mismo género femenino, asignando a partir de un determinado caleidoscopio de significantes un lugar y un destino diferencial para la mujer «sucia» y otro espacio y significantes para la que se denomina «limpia y pura» (Chacón, 1992: 23).

En Costa Rica, el control de la mujer en el ámbito de la sexualidad claramente difundido por la iglesia, respondía también a los intereses económicos estatales y empresariales abanderados por la expansión cafetalera durante el siglo XX, en la que no existía cabida para una sexualidad propia, según Flores (2007: 30) «la domi- 
nación concomitante giraba en torno a la desexualización del deseo y la negación de las pasiones carnales en la feminidad». Todo esfuerzo se dirigió a invisibilizar la existencia de una sexualidad femenina y se normalizó la idea de vaciar a las mujeres de todo contenido y placer sexual para ser una «buena mujer».

Marín (2007) hace un detallado estudio sobre la historia de la prostitución en Prostitución, honor y cambio cultural en la provincia de San José de Costa Rica: 1860-1949, haré referencia a su investigación por los detallados aportes históricos, no sin antes señalar que el enfoque del autor no necesariamente representa la postura política de la autora/investigadora. En ocasiones el texto se refiere a la cantidad de mujeres que fueron consideradas prostitutas, sin embargo, se omite un análisis detallado de los parámetros de moralidad que se manejaban en la época para explicar la razón por la cual todas las mujeres serían consideradas como tal. El estudio no retoma esta reflexión política feminista como un aspecto importante dentro del análisis histórico de la prostitución. Por otra parte, considero importante la resignificación del concepto «clientela» ${ }^{6}$, el cual debería sustituirse por «hombres que consumen prostitución».

Hecha la aclaración y siguiendo con los hechos históricos sobre la construcción de la feminidad costarricense, esa preocupación por diferenciar a las mujeres honestas de las mujeres públicas tenía como propósito principal «ordenar la sociedad costarricense en la nueva lógica productiva y social donde la mujer no solo seguiría transmitiendo el patrimonio familiar sino que también aseguraría una descendencia lozana y trabajadora» (Marín, 2007: 89). Esta obsesión por el nuevo orden determinó que algunas autoridades decidieran perseguir a todas las mujeres que resultasen enfermas de algún mal venéreo, aunque, como señalaremos más adelante, el mal haya sido transmitido por la pareja o bien haya sido el resultado de un diagnóstico médico equivocado (esto último, según Marín muchas veces ocurría).

Es indispensable dimensionar que la mujer diagnosticada de una enfermedad venérea, era instantáneamente considerada «mujer pública», una única prueba sanitaria era lo que determinaba si una mujer era o no prostituta, sin ni siquiera suponer que eran los hombres quienes practicaban casi en su totalidad, un sexo promiscuo y por tanto, eran los principales transmisores de las enfermedades.

Con relación a esto, resulta muy conveniente citar a Patricia Alvarenga quien detalla los discursos sobre sexualidad masculina que circulaban a inicios del siglo $X X$, uno de los tantos, defendía esa «supuesta voracidad sexual que debe, aún con los riesgos de las enfermedades venéreas, ser satisfecha» (Alvarenga, 2012: 39). Lo anterior confirma que no existía, como podemos afirmar que no existe hoy día, un discurso que condene el placer masculino, mientras que para las mujeres en la épo-

6 La «clientela» hoy se redefine como «hombres que consumen prostitución», de lo contrario se sitúa cierta responsabilidad histórica en las mujeres (el término cliente se puede comprender como el término utilizado en la época, pero no en el momento en el que fue desarrollada la investigación). Se pudo haber reflexionado y recomendado por ejemplo, la necesidad urgente de complementar el estudio, incorporando el comportamiento de los hombres que consumían y aún hoy consumen prostitución y sobre la masculinidad hegemónica presente en la época. 
ca que se estudia, el deseo "se convierte en sinónimo de perdición» (Alvarenga, 2012: 39). Aunque, por otra parte, la misma autora se refiere a ciertas posiciones de izquierda a inicios del siglo $X X$, que al parecer debatieron nuevas ideas para desculpabilizar a las mujeres, no profundiza en ello.

Mientras el estudio de Marín no posee un enfoque feminista, la conocida autora costarricense Yadira Calvo reivindica desde el discurso feminista con la expresión: «todas somos putas y locas». A partir de su interpretación del significado de prostitución, o de mujeres públicas en la época, primeramente nos introduce en la historia antigua con este texto sobre la prostitución:

Mucho antes de que santos e inquisidores relacionaran la maldad de todas las mujeres con el sexo, y consideraran insaciable en ellas la lubricidad, que las volvía presas fáciles del diablo, el antiguo testamento aparece preocupado por las rameras, pintadas como promesas de goce y amenazas infernales (Calvo, 2013: 194).

Este concepto de maldad e infernabilidad asociado al cuerpo de las mujeres, llamadas públicas, caló fuerte en el imaginario social, el cual sería sostenido por las autoridades de la iglesia tras la reforma social. Podríamos decir hasta el día de hoy que con este concepto histórico cayó todo el peso para juzgar a las mujeres en prostitución desenfocando para siempre el hombre que demandaba la prostitución. Calvo continúa historizando los conceptos de prostitución y nos señala que en los tiempos cristianos: «se empezó a sospechar que el sexo femenino entero cojeaba del mismo pie» (Calvo, 2013: 194).

En otras palabras, no se afirmaba directamente que todas lo fuéramos, pero sí que todas éramos "propensas al placer sexual», por lo tanto, la observación y el control social sobre las mujeres era, según los hechos, indispensable. Estas sospechas desde luego eran más ciertas o más probables en tanto más pobres, más alegres, menos hogareñas, menos activas en el hogar, o más independientes fueran las mujeres. En la mira estaban, en primer lugar las «mujeres solas» que frecuentaban lugares públicos y sobre todo mujeres dedicadas a prácticas ancestrales, es decir, las llamadas brujas. Para Calvo lo que estos textos resumen o dan a entender es que: «[...] a la larga no es solo que las putas sean brujas, o las brujas sean putas, sino que todas las mujeres son putas y brujas» (Calvo, 2013: 194). Las anteriores citas podrían explicar el por qué en la práctica de la prostitución, históricamente encontraremos una tendencia a culpabilizar ciegamente a las mujeres, olvidando el análisis sobre la masculinidad.

Así como hemos señalado, la redefinición de roles de género influyó en la transformación de actividades femeninas antes lícitas (como fue el caso de las parteras y curanderas, que pasaron a ser consideradas ilícitas a partir del siglo XIX), parte de esas transformaciones que más impactó a las mujeres en esta Reforma Social fue la creación de un protocolo de sanidad que dictaminó quienes eran mujeres públicas o prostitutas. Fue clara la persecución de las mujeres llamadas «ilícitas» tras la imposición del rol de la «mujer idealizada» que lo que pretendía era la construcción de una mujer sumisa, dentro del hogar y totalmente controlada: 
Al igual que las parteras, las mujeres solas, concubinas, jefas de hogar, viudas, jóvenes y madres solteras comenzaron a ser supervisadas por los criterios sanitarios. Las leyes de prostitución comenzaron a sancionar a estas mujeres como meretrices (Marín, 2007: 37).

Otra de las figuras que participaron del nuevo orden fue el sistema policial como uno de los principales denunciantes de las supuestas «mujeres públicas», parte de su labor era sostener y reproducir el ideal de mujer honesta, según Marín:

[...] es decir mujeres gobernadas por un varón, que tuvieran trabajo, que no escandalizaran en su comunidad y que si tenían concubino este fuera estable. A estas directrices unían su propia visión de lo que debería ser una mujer honrada; interpretación creada por sus propias experiencias como lo considerado normal, lectura que muchas veces era dada por su acervo cultural, comunal y familiar (Marín, 2007: 199).

Fue relevante construir y seguir sosteniendo ese imaginario social a partir de la separación definitiva de dos tipos de mujeres, cualquiera de las dos situadas en el límite de una feminidad y sexualidad terriblemente destructiva, sin posibilidad de términos medios: o pertenecían al grupo de «madres y esposas santas perfectas» sin goce ni acceso posible a una vida sexual plena libre de violencia, o pertenecían al tipo de mujeres conocidas como «mujeres públicas o de la calle».

Alvarenga también se refiere a estas oposiciones binarias que reprodujeron dos imágenes femeninas extremas, según la autora: «A la mujer dulce y pura corresponde la mujer malvada o maldita (es decir que aunque no es mala está destinada a la perdición). No existen "grados o niveles" de pureza de bondad o de delicadeza» (Alvarenga, 2012: 37). Según Flores las relaciones fuera del matrimonio (para las mujeres) fueron consideradas inmorales y satánicas con todas las connotaciones que estos adjetivos implicaron:

[...] falta de pudor, vergüenza, deshonestidad. Las rígidas regulaciones morales impuestas al comportamiento sexual femenino, implicaban la interiorización de una autoconciencia respecto a las sexualidades lícitas e ilícitas [...] (Flores, 2007: 40).

\section{Enfermas mentales}

Más que las regulaciones e implicaciones que esta nueva concepción de pureza femenina tuvo para las mujeres, es relevante evidenciar que las mujeres transgredieron esas manifestaciones de violencia a la que tantas veces estuvieron expuestas, estas reacciones provocaron otras consecuencias, por ejemplo que fueran etiquetadas de enfermas mentales. Se inicia entonces una nueva persecución por trastornos mentales, es decir, además del control de sus cuerpo, sin derecho a transgredir, sin derecho a la protesta frente a la violencia sufrida eran diagnosticadas de «locas e histéricas». Estos actos de agresión son representados de múltiples formas en la obra «Vacío», que más adelante se expondrá. Como se ha venido mencionando, 
las reformas sociales que las clases dominantes configuraron entre 1860 y 1949 se basaron en disciplinar las costumbres de las clases populares, según Marín (2007: 66) «con el fin de adecuarlos a los nuevos sistemas de producción que exigía el capitalismo agrario».

Así pues, controlar las costumbres fue un aspecto importante dentro de esta reforma social. No podemos entender las finalidades de dichas reformas si no tenemos claro que controlar las costumbres, pero sobre todo determinar la peligrosidad era el propósito principal, todo esto con la finalidad de ir justificando las medidas e instituciones que posteriormente fueron las encargadas de dar seguimiento. Dicho lo anterior, las políticas reguladoras del cuerpo y la vida de las mujeres, hicieron que fácilmente todas las mujeres fueran calificadas como prostitutas. Así por ejemplo, según la actividad reguladora sanitaria y policial a cualquier mujer era considerada como "caída y peligrosa y entraría a figurar en los registros antivenéreos como meretriz» (Marín, 2007: 67).

Para la Ley de higiene de 1875 lo que procedía era enlistar a todas aquellas mujeres que rompieran con el prototipo de moralidad definida por ley, supuestamente la labor de los funcionarios sería controlar a las mujeres que ejercieran la prostitución. Sin embargo, estos conceptos estuvieron bastante confusos, es fácil deducir cierta arbitrariedad, como el propio Marín señala: «esto se tradujo en la realidad en una mayor persecución de cualquier mujer que quebrantara la amplia imagen de decencia que poseían las autoridades medias y sus subalternos» (Marín, 2007: 95).

Lo anterior permite comprender cómo la sexualidad femenina fue construida a partir del temor, del señalamiento de un supuesto descontrol pasional femenino que desterró a las mujeres a una pureza corporal y mental, pues de lo contrario, todas eran consideradas "prostitutas». Para las mujeres provenientes de sectores populares, estas prácticas sexuales se asociaban con comportamientos ilícitos: ebriedad, conductas sexuales indebidas y nunca con la miseria, la pobreza o la violencia vivida. De acuerdo con la investigación de Marín, el Código Penal de 1880 fue implacable en cuanto a su tipificación de delitos que a partir de ese momento debía vigilar la policía prioritariamente, Marín detalla:

Esta tendencia jurídica se acercó mucho a la planteada por Marc Berliere para Francia del siglo XVIII; según él: la institución policial dedicada a la vigilancia de las costumbres tendió a inspeccionar a todos los sectores populares considerándolos como potencialmente peligrosos (Marín, 2007: 73).

Foucault (1993) ya lo había señalado en sus ensayos sobre la locura, esa relación entre las regulaciones sobre sexualidad, consideradas pecados y hechos satánicos, y cómo esto se llegó a vincular con la definición de mujeres públicas y posteriormente insanas. Desde luego, de allí viene la influencia en la medicina y psiquiatría en nuestro país, que en el párrafo anterior refiere Marín. Según Foucault, en la época se predicaba (1993a: 63): «[...] hay que pagar su deuda a la moral pública, y hay que prepararse, por los caminos del castigo y de la penitencia, a volver a la comunión de la que han sido excluidos por el pecado[...]». Dentro de este contexto las mujeres fueron las más inspeccionadas y las más sospechosas de ser posibles extraviadas y 
de gran peligrosidad.

Tanto para los hombres como para las mujeres la soltería y la juventud representaban un riesgo que les conduciría hacia la insanidad mental, según el enfoque positivista, los y las jóvenes desarrollaban o podrían despertar «predisposiciones patógenas». Flores (2007: 72) señala cómo la juventud era concebida como un riesgo: «La evolución del sujeto adulto, enfrentándose a los riesgos de la vida, implicaba una lucha constante entre los impulsos generadores de insanidad y la contención de descontroles internos».

Si bien es cierto, según la anterior cita, para ambos, hombres y mujeres, la única salida era la unión matrimonial, para las mujeres se convertía en una carga mucho mayor, además de que significaba su «cura inmediata» la mujer representaba ese complemento de la «individualidad masculina». Flores (2007: 73) relata que para la época «la mujer garantizaba la mediación de las relaciones de pareja y de las sexualidades a través del lazo matrimonial. Su presencia dulce y discreta evitaba el tentador retorno a los deseos no regulados».

Por otra parte, con el matrimonio se establecía el control de las pasiones femeninas, en otras palabras: una mujer sola era ya un factor de riesgo en sí mismo y como lo hemos mencionado, los criterios de persecución de las mujeres por sus conductas sexuales no se hicieron esperar. A lo anterior se suma la fundación de las cárceles, en el marco de una política penitenciaria y la corrección moral de los reos que constituirían los sectores populares considerados más peligrosos. Según Marín (2007: 80): «uno de esos grupos era el de las mujeres solas, concubinas, madres solteras y prostitutas josefinas, las cuales fueron equiparadas muchas veces como rameras profesionales».

Así, la estructura carcelaria impactó en las reformas y «roles aleccionadores» para las mujeres. En este contexto estuvieron muy presentes las instituciones clericales que fueron centrales en la labor de disciplinamiento. Para Marín (2007: 81): $«[\ldots]$ las supuestas mujeres deshonestas o rameras fueron a expiar sus conductas a un reclusorio [...] a las que no seguían el nuevo camino guiado por los religiosas $[\ldots]$ eran amenazadas con penas mayores».

¿Serían estos criterios una forma de garantizar que las mujeres siguieran el camino hacia el matrimonio y la familia? El criterio de la mujer casada fue uno de los principales para la definición de honestidad, el estado civil en las mujeres era tan relevante que incluso una mujer que trabajara en el espacio público como una mujer obrera implicaba que al ser parte del mundo urbano e independiente y por lo tanto, «ajena al hogar» era una «mujer pública». Según Marín (2007: 276): «Esa característica las convertía, según los ojos inquisitoriales de las autoridades, en damas potencialmente peligrosas, máxime si eran concubinas o solteras».

Por otra parte, en ese escenario de persecución, como ya hemos mencionado, no podía faltar la figura de la medicina, pero sobre todo, los diagnósticos de insanidad mental y los sanatorios u hospitales mentales. Interesantísimo como Flores (2007) señala que en el proceso del diagnóstico médico entre los años 1892 y 1910 se inician terminologías como «nociones científico-morales» (Flores, 2007: 75). En esos diagnósticos se hacía una referencia para describir el proceso por el cual el deno- 
minado «deterioro moral» finalizaba en casos de insanidad mental. En la segunda parte se muestran algunos extractos de los historiales clínicos que hacían referencia a estos supuestos estados de insanidad.

Por ejemplo, entre las enfermedades que las mujeres padecían estaba la famosa «histeria» considerada una enfermedad femenina. Muchas son las definiciones y afirmaciones de la histeria: que si por falta de sexo o que si por exceso de pasión sexual, la cuestión es que de nuevo se divulgaba como una enfermedad que hacía referencia a la conducta sexual de las mujeres. Se definía a una mujer con exceso de pasión como pública o prostituta, además existía la idea de que las prostitutas se hacían «histéricas» por la masturbación. Rachel Maines (1999: 46) destaca la definición sobre histeria que la medicina clásica promovió como: «El trastorno en consecuencia de la falta de suficiente copulación, de la falta de gratificación sexual o de ambas cosas». Hasta el mismo Galeano citado por Maines, se refería como la causa principal de la histeria radicaba en la privación sexual, eran especialmente vulnerables las mujeres apasionadas.

Para las mujeres, los estados de locura sobre todo la llamada «locura congénita» iniciaba su descripción con los signos de «conducta inmoral» como por ejemplo «descontrol y desnudez» entre otras conductas:

En los cuados denominados «locuras congénitas» era frecuente que los estados de excitación como -descontrol, desnudez, risa, furia o inquietud- se asociaran con la apariencia corporal de las mujeres internadas, fueran percibidos como «atontamiento o idiosía» (Flores, 2007: 98).

Con lo anterior se evidencian las referencias que se hacían a partir del cuerpo femenino, y cómo se construían signos clínicos para juzgar el comportamiento de las mujeres. En otro de los relatos, llamados también: «idiotismo» aparecen descripciones médicas como la siguiente: «se excita más de lo natural» (Flores, 2007: 98-99). Esto hace que surjan las siguientes preguntas: ¿Qué tan natural era la excitación femenina? ¿Cómo era considerada la excitación femenina? Si es que alguna vez pensaron que existiera. Flores subraya:

Probablemente por eso, las descripciones médicas exponían con bastante laxitud lo incorrecto de las emociones expresadas por estas mujeres: sus miedos eran infundados, su llanto sin razón, su excitación más allá de los natural (Flores, 2007: 99).

\section{Interpretación de escena/momento}

En esta segunda parte del artículo se analizan los momentos/escenas de la obra «Vacío», que mejor representan las vivencias de las llamadas mujeres públicas. ¿Cuáles fueron los elementos considerados en esta lectura? ¿Cómo se llega a un análisis feminista a partir de la observación de la obra? Un antecedente importante fue la investigadora Susana Carro y su texto Mujeres de Ojos Rojos (2010), su lectura parte de las categorías de lo público y privado mientras que para la investigación, de la cual se desprende este artículo, el análisis se realiza a partir de la expropiación del cuerpo 
femenino, según Carro (2010): «en su análisis decide no centrarse en elementos formales del arte sino en los discursos y las formas en las que se evidencia en las obras».

Por otra parte, para la pregunta: ¿Existe una única forma de hacer un análisis feminista? Hidalgo (2007: 190) nos aclara: «La obra de arte es un hipertexto con posibilidad de un sinfín de lecturas, según el espectador y el momento histórico en el que se da, por un lado, y en el que se lee o se realiza una aproximación reflexiva, por el otro». Como un gran aporte, Gaínza (1994: 11) nos recuerda que: «Los textos artísticos son, ante todo, articulaciones de sentido, como cualquier otro texto». Finalmente se concluye que es a partir de los elementos significativos que se identifican en las obras; con la lectura de diversas autoras y autores y sobre todo al dialogar con las artistas, como se va articulando la interpretación, todo permeado por el ojo crítico de la investigadora. De lo anterior subrayo la importancia del proceso personal y creativo de las creadoras, como un aspecto vital para un análisis feminista. Vale destacar que ésta es una de las principales diferencias, que según la lectura del crítico teatral francés Pavis (2011) encuentro entre un análisis feminista y una crítica de arte. Pavis inicia cuestionando el tipo de análisis «de reconstrucción» según el obsoleto, pues tiende a analizar declaraciones e intenciones de los y las artistas, lo que considera innecesario. El proceso histórico de la artista (creativo y personal) toma un enorme significado para un análisis feminista, es precisamente este tipo de indagación la más significativa en una lectura feminista.

Antes de describir algunas escenas de la obra «Vacío», es importante recordar que esta obra entremezcla relatos reales sobre los historiales clínicos de las mujeres que estuvieron hospitalizadas en el psiquiátrico por diversas razones, casi todas producto de conductas «rebeldes» que transgredían la norma de la «mujer-madre y esposa perfecta» o simplemente como respuesta a situaciones de violencia extrema. Lo significativo de esta obra es que las realidades de estas mujeres no se representan en salas de hospitales, sino que se reconstruyen y resignifican a través de la creación de un espacio y un ambiente escénico que a manera de burdel (lo cual se ampliará más adelante) reubica todas las formas en las cuales la feminidad fue construida por el patriarcado, que en aquel momento histórico estaba fuertemente dirigido por el poder de la medicina, el Estado y la iglesia católica. A continuación se muestran algunas escenas y parte del análisis.

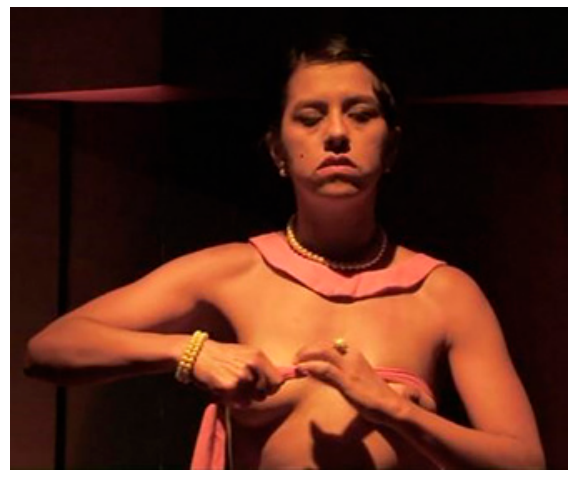

Fig. 1. Vacío (Roxana Ávila, 2013). Teatro de la Aduana. Actriz: Grettel Méndez. 


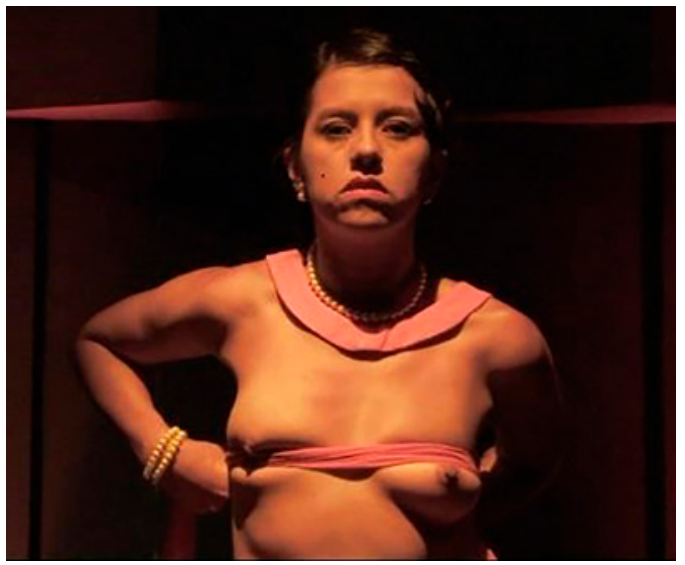

Fig. 2. Vacío (Roxana Ávila, 2013). Teatro de la Aduana. Actriz: Grettel Méndez.

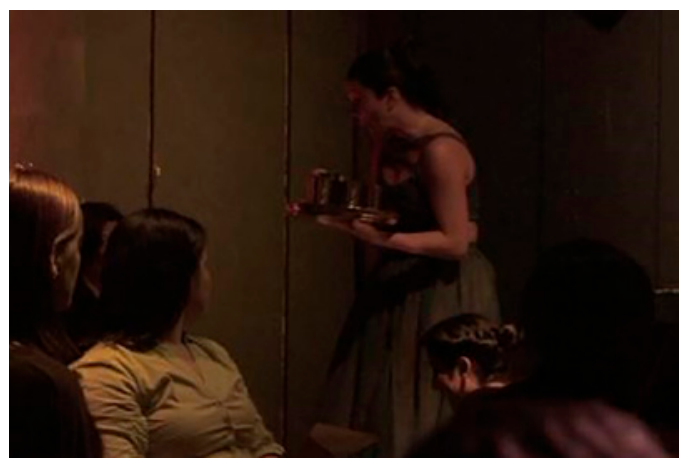

Fig. 3. Vacío (Roxana Ávila, 2013). Teatro de la Aduana. Actriz y bailarina: Erika Mata.

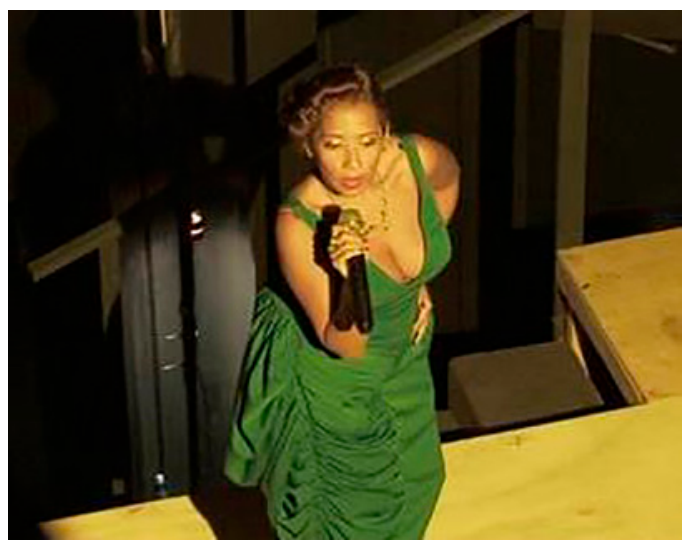

Fig. 4. Vacio (Roxana Ávila, 2013). Teatro de la Aduana. Actriz y cantante: Maria Luisa Garita. 


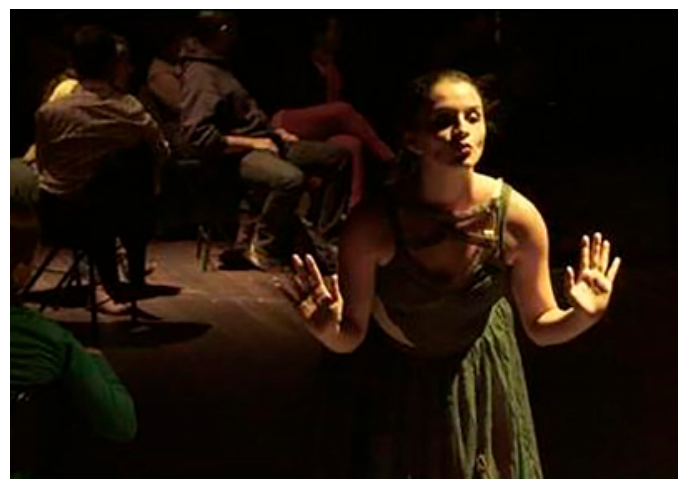

Fig. 5. Vacío (Roxana Ávila, 2013). Teatro de la Aduana. Actriz y bailarina: Erika Mata.

En esta secuencia de imágenes correspondientes a la obra «Vacío» (de Roxana Ávila) se intentan retratar de muchas formas las llamadas «mujeres públicas». Al mismo tiempo aparecen escenas en las que se expone la corporalidad femenina con gran fuerza visual, la obra presencia una corporalidad femenina asociada a la sexualidad negada, a la maternidad, representaciones de violencia y auto castigo. Aparecen desde artistas que simulan actos sobre sus cuerpos, acompañados de expresiones fuertes como las primeras imágenes ( 1 y 2 ) en las que se observa una mujer (interpretada por la actriz Grettel Méndez) deformando sus senos, usando un pedazo de vestuario con el cual va presionando partes de su cuerpo. Su rostro expresa indiferencia, disimulando el dolor, o bien demostrando no tener más salida que aguantar el dolor.

Otras escenas personifican «meseras o saloneras» que se dedican a servir al público, mientras cantantes y bailarinas interpretan canciones como por ejemplo la canción «Camarera» ${ }^{7}$ (imágenes 3,4 y 5). Estos momentos son acompañados de lectura de textos que también se relacionan con relatos de mujeres, por ejemplo: «Si la esposa ama la bebida y es iracunda, si ama el lujo, si es golosa amiga de visitar. Pendenciera, maldiciente, hay que sufrirla» (Ávila y Morera, 2012: 188).

En otras escenas posteriores mientras las artistas cantan las canciones «Cucurrucucú Paloma» ${ }^{8}$ son leídos los siguientes textos:

[...] La madre es una moral insanity y lleva mala vida [...] abandonó el hogar conyugal y se fue a vivir con su hermano, dice que detesta la casa del esposo. Excitación sexual marcada, Apetito caprichoso. Historial clínico 9587 (Ávila y Morera, 2012: 189).

7 «Camarera» de Antonio Machín. Canción bolero- popular de los años 70, se refiere a un hombre, cliente de un bar que tiene una relación de confianza con una camarera, quien se convierte en su compañera y le acompaña en sus «supuestos» momentos de tristeza y desamor.

8 La canción "Cucurrucucú Paloma» es autoría del compositor mexicano Tomás Méndez. Es una canción romántica y dramática que relata el sufrimiento de un hombre por una mujer. 
Esta obra tiene la particularidad de entremezclar el abordaje de las distintas temáticas con técnicas multisensoriales de forma casi imperceptible, para la audiencia no es posible mantener la atención del total de detalles que la obra presenta, porque utiliza notas, música, movimientos y frases coreográficas, artistas que se acercan al público para susurrar un texto, elementos visuales, entre otras expresiones y todo esto ocurre en un mismo momento. Además por la morfología del espacio escénico que no contiene solo un escenario frontal, sino que se distribuye en todo el lugar, provoca que una parte de la audiencia observe un momento de la obra, mientras otro grupo disfrute de otros. En este ir y venir de momentos es difícil capturar la totalidad de la puesta en escena. Asimismo, una característica de la obra es la presentación de los argumentos de manera entrecruzada, lo que la hace realmente atractiva, dinámica y altamente entretenida. Dicho esto, aunque se hizo un esfuerzo por abordar e identificar las distintas temáticas que interesaron en la investigación, no es posible abarcarlas en su totalidad, por la dinámica misma de retomar un tema que luego abandona, o reaparece desde otras simbologías.

El abordaje de «las mujeres públicas» es uno de esos temas que se interpreta de formas distintas y esto responde a la realidad de las mujeres y los mandatos terriblemente violentos a los que se exponían, lo que las colocaba siempre como «mujeres prostitutas», «mujeres de la mala vida» o «mujeres públicas». Vale reiterar que si por decisión o por situación económica una mujer trabajaba fuera de casa, ya era considerada una mujer pública, si una mujer rompía su relación matrimonial por manifestaciones de violencia extrema (como sucedía con la mayoría de ellas) era considerada una mujer insana y así podemos imaginar cuántas razones diversas terminaban por señalar a una mujer como «prostituta».

Por otra parte y en relación con la construcción de la sexualidad, las mujeres «solteras» que tenía varias parejas, o frecuentaban lugares públicos eran sin duda «mujeres de la mala vida». Todas estas prácticas ajenas a las conductas esperadas por las mujeres se articulan en la obra de manera cruzada con los temas que se han venido exponiendo como la maternidad y la labor de madre-esposa perfecta entre otros.

Otra de las escenas específicas que retrata la supuesta conducta de una mujer considerada "pública» se hace con la lectura del siguiente relato: «Parece que ella ha sido muy mala y arrastrada en la calle y la mala vida es la causa de la histeria». Historia Clínica 9041 (Ávila y Morera, 2012: 191), lo que además, hace que esta escena se convierta en detonante o momento de explosión para la obra. La lectura se acompaña de la interpretación «Piece of my heart» de Jannis Joplin, canción que se caracteriza por una gran potencia, la artista irrumpe con un fuerte grito, para terminar la escena con un silencio absoluto.

Por último, también en esta parte de la obra (imágenes 4 y 5) se ejemplifica el estereotipo y mito de la belleza y la sexualidad a partir de ser «bellas y perfectas para ellos, para los esposos». La obra personifica a manera de parodia o burla la canción «Happy Birthday» y la cantante simula los movimientos sensuales de Marilyn Monrroe, mientras que al mismo tiempo las otras artistas recrean movimientos sensuales y burlescos. La anterior escena se acompaña de la lectura del siguiente texto: 
«Tú debes en forma siempre estar. Mantente bien arreglada, eso debes procurar. Te miran, te mira, no puedes olvidar. Recuerda tu apariencia, mo-der-na Si te miran que te vean perfecta» (Ávila y Morera, 2012: 192). Es importante reiterar que la obra recrea la idea de un burdel, es una obra que no se realiza en un teatro con escenarios convencionales, el espacio simboliza un espacio público que bien puede ser un burdel o un bar, para este extracto del análisis sobre mujeres públicas este elemento artístico resulta relevante, razón por la cual a continuación se detalla.

\section{Un burdel tomado por ellas}

Detrás de la intención de construir el escenario como un burdel, como un espacio público, en este caso, se mueve una interesantísima intención de recrear y re-apropiarse desde las mismas mujeres, de un espacio que históricamente ha sido diseñado y controlado desde una lógica masculina.

En esta ocasión, se podría interpretar que este burdel es protagonizado por ellas, por las mujeres, ellas contando su historia, ellas expresando con su cuerpo, ellas recuperando los hechos desde la patologización, la maternidad y la violencia. Las mujeres, las protagonistas en su totalidad, toman la palabra a través de un megáfono principal (en la voz de la actriz Andrea Gómez) que va relatando los historiales clínicos reales, cantantes, músicas y bailarinas, toman ese espacio público transformándolo en uno «solo para mujeres».

Un espacio como es el burdel, el prostíbulo, se amplía simbólicamente, pues no únicamente hace referencia al burdel sino a otros espacios como podrían ser los bares, también ajenos a las mujeres, destinado únicamente a los hombres, esta vez recuperado para y por las mujeres.

La vestimenta simula las mujeres llamadas «públicas» de la época, así como la presencia de algunas de las actrices que se encuentran siempre en actitud de sumisión, atención, servicio, y docilidad entre otras, lo que se complementa con el mensaje de las canciones. Con las imágenes se muestran distintas escenas que podrían estar representando la construcción de la sexualidad femenina, a partir de la expropiación del cuerpo, de la negación del placer, sustituido en su totalidad por el deber ser de maternidad y esposa.

Justamente sugiere también la sexualidad negada o escindida para las mujeres, que por la negación del placer se enfrentaban a complicadas formas de relacionarse con su cuerpo, con su corporalidad. En las primeras dos imágenes, se trata de un acción en que la artista parece estar oprimiendo su cuerpo, sus senos, símbolo de su sexualidad negada, pero símbolo también de la maternidad. ¿Se podrían interpretar como la imposición de un cuerpo solo para la reproducción? Por ejemplo, nótese que en los textos anteriormente presentados se describe el diagnóstico que se hace de una mujer: «Excitación sexual marcada y apetito caprichoso»; razón por la cual fue internada en el hospital psiquiátrico. Aunque no se detallan con exactitud los comportamientos o mal llamados «síntomas» que provocaron ese supuesto cambio de actitud, el escrito es suficiente para comprender la represión sexual y los mandatos tremendamente crueles que recaían sobre las vidas de las mujeres. Lo 
anterior explica por qué las llamadas «mujeres públicas o prostitutas» terminaron siendo internadas y hospitalizadas, finalmente se les consideró también sujetas de una especie de locura e insanidad mental como parte de la invención y la patologización que sufrieron.

\section{Cierre}

Como reflexión final, aunque en otro contexto geográfico e histórico del que hemos venido describiendo en este artículo, Didi-Hubberman realiza un exhaustivo estudio sobre la invención de la locura de las mujeres en la Francia de los siglos XVIII y XIX, en el que señala la existencia de hombres histéricos, sin embargo no hubo indicios fotográficos al respecto, únicamente hay referencia de fotografías de mujeres diagnosticadas histéricas. ¿Por qué? ¿Será porque el cuerpo de las mujeres fue siempre menos propio que el de los hombres, menos perteneciente a ellas mismas, más público, más observable, más disponible para todos lo que quisieran observarlo?

Siguiendo a Didi-Hubberman (2007: 111-112): «Se trata sin duda de una táctica de diferencia entre sexos. Que sea elevada al nivel de un "temperamento" no cambia nada...». Tomaremos la extraordinaria metáfora de «la medicalización del burdel» que permite analizar la vinculación que finalmente existe entre un cuerpo femenino supuestamente «público» desterrado para siempre a la cosificación y utilización de otros, y una feminidad «insana» que será representada por una mujer trastornada y hospitalizada como castigo por su «moral insanity» que no fue capaz de seguir las normas de santidad que como madre esposa le fueron asignadas. El hospital es a la mujer «insana» lo que el burdel es a la mujer «pública». El autor expresamente hace referencia a una similitud interesante entre la figura de la interna, "supuesta histérica de la prostituta», relación o comparación que sustenta desde la utilización y exposición extrema del cuerpo femenino. Ubicando el cuerpo y la sexualidad femenina en el lugar de la sexualización malsana, desde la corporalidad extraña, enferma e incomprendida, se refiere al concepto de «medicalización del burdel» con el que finalmente comprendemos el vínculo que históricamente existió entre el burdel y el hospital, en ambos espacios se hizo uso del cuerpo femenino para disfrute «también» de las autoridades médicas, en una época conformada por hombres:

El asilo se redefine, por ejemplo, como lugar invertido, medicalizado, del burdel [...] porque entre la histérica y la prostituta tan sólo hay un paso, el de franquear los muros de la Salpêtrière y encontrarse en la calle [...] En resumen, todos los procedimientos de la invención generalizada de una sexualidad de la época entienden aún la histeria como un haber de la feminidad (Didi-Huberman, 2007: 112).

Las etiquetas de locas y putas nos han perseguido por siglos a las mujeres y existe una estrecha relación entre la construcción de la locura femenina, la patologización y la intención socio-política y religiosa de etiquetar a las mujeres entre «públicas», es decir insanas, y las mujeres «madres y esposas». Partiendo de esta 